\title{
Research on the Construction of Blended Teaching Mode Based on Flipped Class-Taking the Undergraduate Discrete Mathematics Course as an Example
}

\author{
Yongxia Zhang1 ${ }^{*}$, Wei Liu² \\ ${ }^{1}$ School of Computer Science and Technology, Shandong University of Finance and Economics, Jinan, China \\ ${ }^{2}$ School of Business Administration, Shandong University of Finance and Economics, Jinan, China \\ Email: ^sdu_zyx@hotmail.com
}

How to cite this paper: Zhang, Y. X., \& Liu, W. (2021). Research on the Construction of Blended Teaching Mode Based on Flipped Class-Taking the Undergraduate Discrete Mathematics Course as an Example. Creative Education, 12, 957-965. https://doi.org/10.4236/ce.2021.125069

Received: April 3, 2021

Accepted: May 3, 2021

Published: May 6, 2021

Copyright ( 2021 by author(s) and Scientific Research Publishing Inc. This work is licensed under the Creative Commons Attribution-NonCommercial International License (CC BY-NC 4.0). http://creativecommons.org/licenses/by-nc/4.0/ cc) (i) \& Open Access

\begin{abstract}
In the traditional teaching mode, students passively receive knowledge, which does not fully stimulate their enthusiasm and innovation. With the development of the Internet, blended teaching mode comes into being and has become one of the main ways of teaching reform. We introduce the blended teaching mode firstly. And then, we take the undergraduate discrete mathematics course, which is one of the most important courses of computer science, as an example, analyze its characteristics and the shortcomings of the current teaching mode. The application of blended teaching mode is imperative. Finally, we explore the application and design of the blended teaching mode based on flipped class on the undergraduate discrete mathematics course.
\end{abstract}

\section{Keywords}

Blended Teaching Mode, Flipped Class, Discrete Mathematics

\section{Introduction}

The traditional teaching mode is centered on teachers, textbooks, and classrooms. Teachers systematically explain knowledges in the class and students passively accept. The main characteristics of the traditional teaching mode are as follows.

1) Traditional teaching mode is a kind of instillation education, which ignores the initiative and innovation of students. It is also not conducive to the improvement of learning effects and the cultivation of students' innovative ability. 
With the continuous deepening of new media teaching reform, a variety of new teaching forms have gradually infiltrated, while the current blended teaching mode is still in the exploratory stage.

2) Students have different knowledge bases and learning abilities. Therefore, students have different degrees of acceptance of the same knowledge. The traditional teaching mode takes the class as the unit, where there are usually dozens of students. It ignores the individual differences of students and the teaching effect is uneven.

3) For the continuous adjustment and optimization of the training program, some courses have the contradiction of fewer hours and more content. In the traditional teaching mode, students do not have enough time to think, which makes the teaching effect unsatisfactory (Xue \& Shuangyuan, 2021).

In the current educational environment, the traditional teaching mode has been unable to meet the needs of students. They need more sources of information, such as videos, blogs, e-books, forums, etc. In the "Internet+" era, teaching technological means has become more intelligent, the teaching ecology has become more open, and the relationship between teachers and students has become more equal. It is norm that more emphasis has been placed on the individual learning and online learning. However, it does not mean that any learning must be "Internet+". It is well known that face-to-face is one of the most effective ways of communication. The traditional classroom teaching also has its own unique and irreplaceable role. Based on this, it is determined that teaching will enter a mixed stage. The blended teaching mode that integrates online and offline is necessary. This mode can not only make the teacher play the leading role, but also meet the needs of students for independent learning. Especially with the promotion of new teaching concepts and methods such as MOOCs, micro-classes, and Flipped Class, blended teaching mode has become the most practical and effective teaching mode in the "Internet+" era.

In the followings, we first introduce the blended teaching mode and flipped class in Section 2. Then we take the undergraduate discrete mathematic course as an example, analyze its characters and teaching situation, and make a conclusion that it is necessary to carry out blended teaching mode for this course in Section 3. Section 4 focuses on the design of the blended teaching mode based on flipped class for the discrete mathematics course. Finally, we summary the manuscript in Section 5.

\section{The Concepts of "Blended Teaching Mode" and "Flipped Class"}

Blended teaching mode is an online + offline teaching mode, which combines the traditional teaching method with network teaching method and takes advantage both of them. Blended teaching mode pays more attention on students than teachers as the main body of learning and fully highlights the initiative, enthusiasm and creativity of students. At the same time, it also needs teachers to 
play a leading role in guiding, inspiring and monitoring the whole process. Blended teaching mode focuses on cultivating the learning ability and innovation ability of students, and it is one of the effective methods to deepen the depth of learning (Zhixue, 2021).

Flipped class is a new form of teaching that has emerged in recent years with the rapid development and popularization of the internet especially the mobile internet. It is one of the effective implementation of blended teaching mode. Flipped class readjusts the time arrangement during and after class, and transfers the initiative and decision-making power of learning from teachers to the students themselves. Under this teaching mode, more time in class is used to explain key and difficult points, discuss questions and complete some projects. The learning of basic knowledge is mainly completed online in the off-class by the students independently at any time. Teachers must provide many kinds of electronic resources, including teaching videos, courseware, reference materials, et al. and upload them to the web ahead. Students can make a plan for the speed and manner of learning out of the class based on their own preferences. In order to promote their personalized learning, the teacher can adopt the teaching and collaboration methods to meet the needs of students. In this way, students can obtain more knowledge through practice.

Figure 1 shows the process of blended teaching mode based on flipped class. The teaching process is divided into three stages: pre-class, in-class and after-class. Students learn the basic knowledge using online resources, finish the exercises and record the problems encountered in this process before class. In the class, teachers explain the key and difficult points and organize group discussions. After class, students make a summary, and teachers collect feedback.

The essence of the blended teaching mode is to reverse the process of knowledge transfer and knowledge internalization in the traditional teaching. The traditional teaching mode focuses only on the process of information transmission and ignores the process of information absorption and internalization. Blended teaching mode shifts "Teaching-oriented" to "learning-oriented", and emphasizes learner-centered and increases the interaction between teachers and students, students and students. This mode makes it possible, that giving full

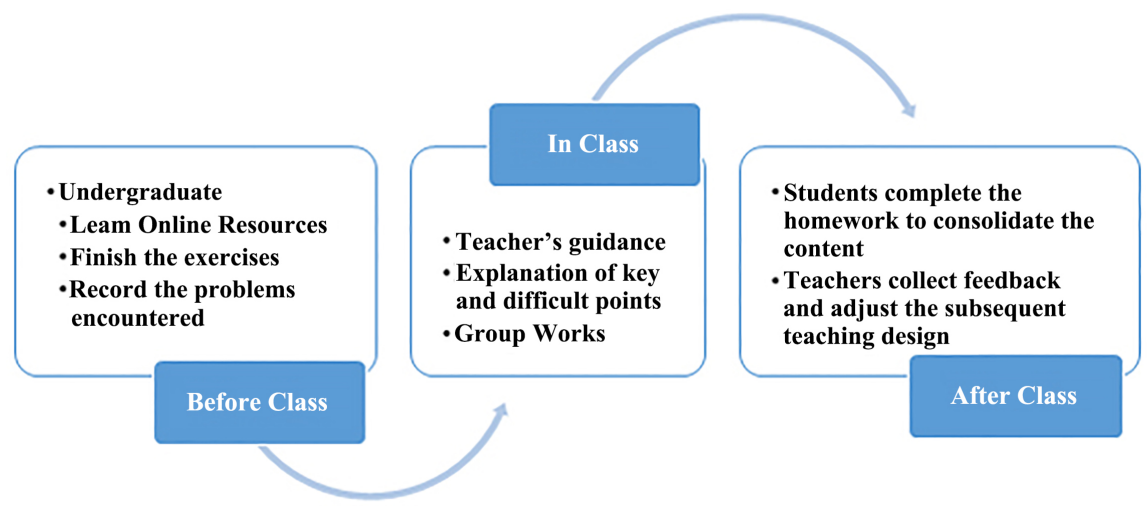

Figure 1. Blended teaching mode process. 
play to the learners' subjective initiative in the teaching process. On the one hand, blended teaching mode can change the traditional way of learning, namely, teachers teaching and students listening. On the other hand, it can stimulate students' enthusiasm for learning and cultivate their enthusiasm and initiative. Flipped class is a thorough subversion of the traditional classroom teaching mode. It will trigger a series of changes in the role of teachers, curriculum models, management model and so on.

At present, many scholars and schools have carried out the practice of blended teaching mode, and achieved good results (Alias, Iksan, Karim, Nawawi, \& Nawawi, 2020; Wang, Chen, \& Li, 2020).

\section{The Characteristics of Discrete Mathematics Course and the Teaching Situation}

\subsection{The Characteristics of Discrete Mathematics Course}

For computer can only process data with discrete structures, continuous and complex data must be discretized first to as the input to a computer algorithm. Discrete mathematics mainly studies the structure of discrete quantities and their relationships. It is one of the basic courses of computer science. The main contents of the discrete mathematics include mathematical logic, set theory, algebraic structure, combinatorial mathematics, graph theory and elementary number theory, et al.

Discrete mathematics course has the characteristics of multiple definitions, strong theory, high abstraction, strong logic, and high difficulty. Through the study of this course, students should be able to form abstract thinking and logical reasoning abilities, and improve their ability to use computers to solve practical problems.

\subsection{Teaching Situation}

At present, the teaching of discrete mathematics course is still mainly adopts the traditional teaching mode, that is, the teacher teaches all contents to students in the class. There are many problems with this teaching mode. The contents of discrete mathematics are informative and complex. For the limited class hours, in the traditional teaching mode, there is only enough time in the class for the teacher to explain the basic knowledge and concepts. As a result, there is no time to expand knowledge and organize discussions to crunching their knowledge. Over time, the students' enthusiasm for learning is decreasing, and the classroom participation becomes few.

For another, even though a large number of definitions and logical reasoning in discrete mathematics are very difficult, there is not enough time in the class to allow students to understand and think deeply in the traditional teaching mode. Furthermore, the students in one class have individual differences in their ability to master the same knowledge. That means the teaching effect cannot be guaranteed. 
Last but not least, in the whole teaching process, due to the limited class hours, it is lack of cultivation of students' innovation. It is difficult to stimulate their creativity and imagination in the traditional teaching mode. Consequently, students lack the ability to solve practical problems using the discrete mathematics course (Wenjin, Weixing, \& Yichen, 2016).

In order to solve the above problems, inspired by the advanced teaching aids, we design a mixed online and offline teaching mode for undergraduate discrete mathematics course. We adopt the network platform for its flexibility and convenience in resource acquisition. At the same time, we assume the main idea of the Flipped Class, transforming the knowledge learning process from "teaching first and then learning" to "first learning and then teaching". In this way, we extend the teaching beyond the classroom, and encourage students to complete the basic knowledge learning initiatively firstly. And then, introduce realistic problems and organize discussion in the class. It is benefit for stimulating students' interest in learning, and improving their enthusiasm in learning (Xiangjie, \& Hai, 2020).

\section{The Design of Blended Teaching Mode Based on Flipped Class for Undergraduate Discrete Mathematics Course}

\subsection{Select Content and Determine the Teaching Mode}

In this paper, we focus on the discrete mathematics course for digital media technology majors, with a total of 32 hours. Discrete mathematics course is rich in contents and has a large number of knowledge points. Due to the limitation of class hours, we should first select the course content according to the specialty characteristics and cultivation scheme requirements. Table 1 shows the discrete mathematics knowledge system and the selected results. The computer system uses binary coding and contains complex logic circuits. Mathematical logic and set theory are closely related to computers. Learning these two parts is helpful to the understanding and design of the computer hardware and algorithms. The major of digital media technology emphasizes the processing of media data such as images and videos et al. Graph theory is a powerful tool. Therefore, we choose mathematical logic, set theory and graph theory as the main teaching contents of the course.

Table 1. Discrete mathematics knowledge system and content selection.

\begin{tabular}{cc}
\hline Section & selected \\
\hline Mathematical Logic & $\sqrt{ }$ \\
Set Theory & $\sqrt{ }$ \\
Algebraic Structure & \\
Combinatorial Mathematics & $\sqrt{ }$ \\
Graph Theory & \\
Elementary Number Theory &
\end{tabular}


Discrete mathematics content varies greatly in difficulty, and it is not ideal for students to learn all the knowledge points by themselves offline. Therefore, we need to choose the appropriate teaching mode according to the difficulty of the chapter content. Mathematical logic requires a lot of logical reasoning skills, which is extremely difficult for students who have not been exposed to logical reasoning. It needs more detailed explanation and more practice. Accordingly, we suggest that the mathematical logic part still adopts the traditional teaching method, that is, the teacher will lecture in the classroom. Relatively speaking, undergraduates have already learned something about sets and graphs theories and now it is an expansion, which is relatively easy. So they can be taught in flipped class. Table 2 shows the discrete mathematics knowledge system and applicable teaching modes.

\subsection{Online Resource Construction}

In the blended teaching mode, the quality of online resources is extremely important, and it seriously affects the effect and depth of students' independent learning.

First of all, the knowledge system should be fragmented. The knowledge points should be divided according to the learning objectives of the discrete mathematics course. Each knowledge point corresponds to a fragment. A 10-minute explanation video is recorded for each knowledge point, which facilitates students' learning at any time. Take the tree section of the graph theory as an example. Figure 2 shows the division of tree-related knowledge points.

For each knowledge point, in addition to recording ourselves, we can also introduce open online courses. The MOOC platform has a large number of national high-quality courses. We introduce the national high-quality course of discrete mathematics taught by Ms. Wang Lijie from University of Electronic Science and Technology of China. In addition to the video, we also set up online self-test exercises for each knowledge point, and set up homework tasks after the chapters. The key knowledge points can be explained with the help of animation

Table 2. Discrete mathematics teaching chapters and teaching mode.

\begin{tabular}{ccc}
\hline Section & Teaching Contents & Teaching Mode \\
\hline Algebraic Structure & Propositional Logic and Predicate Logic & Traditional Teaching Mode \\
Set theory & Set Algebra, Binary Relation and Function & Flipped Class \\
Graph Theory & Graph and Tree & Flipped Class \\
\hline
\end{tabular}

\begin{tabular}{|c|c|c|c|c|c|c|c|}
\hline \multicolumn{8}{|c|}{ Tree } \\
\hline $\begin{array}{c}\text { The } \\
\text { concept of }\end{array}$ & $\begin{array}{c}\text { The } \\
\text { nature of }\end{array}$ & Undirected & \begin{tabular}{|c|} 
Spanning \\
Tree
\end{tabular} & $\begin{array}{l}\text { Minimum } \\
\text { Spanning }\end{array}$ & $\begin{array}{c}\text { Rooted } \\
\text { Tree }\end{array}$ & \begin{tabular}{|c} 
Traversal \\
of Tree
\end{tabular} & $\begin{array}{c}\text { Optimum } \\
\text { Tree }\end{array}$ \\
\hline Tree & the tree & & & Tree & & & \\
\hline
\end{tabular}

Figure 2. Knowledge points division of tree. 
cases as a supplement. It is worth noting that all the content needs to be built online resources, whether using traditional teaching mode or flipped class method.

\subsection{Flipped Class Promotes Teaching}

The implementation of flipped class requires teachers and students to complete some work off class. Before class, teachers should remind students of the resources and exercises that students need to learn. After the students complete the preview, teachers can know how much knowledge the students grasp based the statistics of students' watching videos and completing exercises.

In class, the teacher focuses on explaining important concepts and knowledge points, so as to promote students' internalization of knowledge and improve students' learning efficiency and effectiveness. What's more, in class, the teacher can introduce practical problems, initiate topics, organize discussion and ask the representative to explain their results. In this process, the teacher is responsible for guiding, supplementing and correcting the students' statement. Finally, the teacher should make a summary and extracts the knowledge points and ideas used in solving the problems.

After class, teachers can further give targeted guidance to students with poor learning ability to ensure the integration of teaching effect. Teachers can improve their micro-lesson design and optimize the teaching process based on the collected feedback.

The key to the success of flipped class is the organization of the classroom. For example, how much time in a class should be arranged for reporting and communicating with students, and how much time is needed for making a summary. Teachers must know everything about the content of the class and the overall quality of the students. On the other hand, the difficulty of the content and the number of knowledge points varies from each class. Based on the above two aspects, teachers are required to closely observe the changes of students and know the changes of the course content at the same time. In this way, the class can be organized more pertinently, and the class time and learning effect can be controlled.

In the whole teaching process, the student is the main body and the teacher is the guide. This mode fully mobilizes the initiative and enthusiasm of students in learning. The application of group discussion can cultivate students' teamwork ability.

\subsection{Evaluation System Setting}

Assessment is a common way to measure the effectiveness of teaching. The evaluation of discrete mathematics course generally consists of two parts, the usual grades and the final grades. In the traditional teaching mode, the final grades account for as much as $70 \%$ of the total score. The usual grades are mainly determined based on the student's attendance rate and homework completion. 
Table 3. Composition of evaluation system.

\begin{tabular}{|c|c|c|}
\hline Composition & & Examined Contents \\
\hline \multirow{5}{*}{ Usual Performance (60\%) } & \multirow{2}{*}{ In Class } & Interaction and participation \\
\hline & & Ability to think and solve problems et al. \\
\hline & \multirow{3}{*}{ After Class } & Online resource click-through rate \\
\hline & & Online resource learning hours \\
\hline & & Homework completion, et al. \\
\hline Final-examination (40\%) & \multicolumn{2}{|c|}{ Pay more attention to the test of problem solving ability } \\
\hline
\end{tabular}

Obviously, this method cannot reflect the students' mastery of the course content objectively and effectively. It is also difficult to measure whether the students have achieved the training goals of the course.

Blended teaching mode lays more emphasis on the dominant position of students. It is valuable for the active participation of students. Therefore, we must design a corresponding evaluation system, and pay more attention to process evaluation. So that it can give full play to the guiding and stimulating role of assessment. The new evaluation system is more beneficial to promote the cultivation of students' self-learning ability, innovative spirit and practical ability. To this end, we can achieve this goal by increasing the proportion of the usual performance as shown in Table 3. The usual grades can be set to account for $60 \%$, and mainly includes extracurricular (click rate of online resources after class, learning duration, homework completion, et al.) and classroom performance (class interaction and participation, et al.).

\section{Conclusion}

Give the human by the fish to be inferior give the human by the fishing. Blended teaching mode is one of the most popular teaching methods. The core concept of this teaching mode is "student-centered and learning-centered". Letting students act as active participants can increase their interest in the course, makes it easier for students to understand and master knowledge points, and cultivates their abilities to solve practical problems. At the same time, students also promote their organizational and coordination skills and teamwork spirit when they make discussion in groups in class. Blended teaching is imperative Take the discrete mathematics course as an example, we have explained the design of blended teaching mode based on flipped class. The blended teaching mode can be used in many courses. Currently we are carrying out the practice of blended teaching mode on discrete mathematics course. As the teaching goes on, we can gain more data and experience, and optimize the blended teaching mode of discrete mathematics courses furtherly.

\section{Acknowledgements}

This work is supported by the Humanities and Social Sciences in Universities of Shandong Province (No.J16WJ04) and Shandong University of Finance and 
Economics (No. KCSZ202053).

\section{Conflicts of Interest}

The author declares no conflicts of interest regarding the publication of this paper.

\section{References}

Alias, M., Iksan, Z., Karim, A., Nawawi, A., \& Nawawi, S. (2020). A Novel Approach in Problem-Solving Skills Using Flipped Classroom Technique. Creative Education, 11, 38-53. https://doi.org/10.4236/ce.2020.111003

Wang, J., Chen, G., \& Li, B. (2020). From the Perspective of Blended Teaching: The Application of Fragmented Learning in the Class of Bilingual Teaching. Creative Education, 11, 2213-2217. https://doi.org/10.4236/ce.2020.1111161

Wenjin, Z., Weixing, L., \& Yichen, W. (2016). Flipped Classroom Teaching Mode-Take Discreted Mathematics as an Example. Computer Engineering \& Science, A01, 135-138.

Xiangjie, N., \& Hai, D. (2020). Discussion on the Application of Discrete Mathematics Teaching Model Based on Reversal Classroom. Education Modernization, 7, 156-158.

Xue, X., \& Shuangyuan, L. (2021). Study on Teaching Method of Discrete Mathematics to Wisdom Classroom under Mobile Internet Environment. Journal of Higher Education, 7, 99-102.

Zhixue, H. (2021). Discussion on the Blended Teaching Mode of Online Empowering Offline. Computer Era, 3, 93-96. 